\title{
Multi-risk governance for natural hazards in Naples and Guadeloupe
}

\section{Journal Article}

\section{Author(s):}

Scolobig, Anna; Komendantova, Nadejda; Patt, Anthony; Vinchon, Charlotte; Monfort-Climent, Daniel; Begoubou-Valerius, Mendy; Gasparini, Paolo; Di Ruocco, Angela

\section{Publication date:}

2014-09

\section{Permanent link:}

https://doi.org/10.3929/ethz-b-000088674

\section{Rights / license:}

In Copyright - Non-Commercial Use Permitted

\section{Originally published in:}

Natural Hazards 73(3), https://doi.org/10.1007/s11069-014-1152-1 


\title{
Multi-risk governance for natural hazards in Naples and Guadeloupe
}

\author{
Anna Scolobig $\cdot$ Nadejda Komendantova $\cdot$ Anthony Patt • \\ Charlotte Vinchon • Daniel Monfort-Climent • Mendy Begoubou-Valerius • \\ Paolo Gasparini • Angela Di Ruocco
}

Received: 21 August 2013/ Accepted: 16 March 2014/Published online: 25 March 2014

(C) Springer Science+Business Media Dordrecht 2014

\begin{abstract}
Technical and institutional capacities are strongly related and must be jointly developed to guarantee effective natural risk governance. Indeed, the available technical solutions and decision support tools influence the development of institutional frameworks and disaster policies. This paper analyses technical and institutional capacities, by providing a comparative evaluation of governance systems in Italy and France. The focus is on two case studies: Naples and Guadeloupe. Both areas are exposed to multiple hazards, including earthquakes, volcanic eruptions, landslides, floods, tsunamis, fires, cyclones, and marine inundations Cascade and conjoint effects such as seismic swarms triggered by volcanic activity have also been taken into account. The research design is based on a documentary analysis of laws and policy documents informed by semi-structured interviews and focus groups with stakeholders at the local level. This leads to the identification
\end{abstract}

\footnotetext{
A. Scolobig $(\bowtie) \cdot$ N. Komendantova A. Patt

Risk, Policy and Vulnerability Program, International Institute for Applied Systems Analysis (IIASA), Laxenburg, Austria

e-mail: anna.scolobig@usys.ethz.ch

Present Address:

A. Scolobig

Human-Environment Systems Group, Department of Environmental Systems Science, Swiss Federal Institute of Technology (ETH), Universitätstrasse 22 CHN J72.2, 8092 Zurich, Switzerland

N. Komendantova $\cdot$ A. Patt

Human-Environment Systems Group, Department of Environmental Systems Science, Swiss Federal Institute of Technology (ETH), Zurich, Switzerland

C. Vinchon · D. Monfort-Climent

French Geological Survey (BRGM), Orléans \& Gourbeyre, France

M. Begoubou-Valerius

French Geological Survey (BRGM), Orléans \& Petit-Bourg, France

P. Gasparini · A. Di Ruocco

Center for the Analysis and Monitoring of Environmental Risk (AMRA), Naples, Italy
} 
of three sets of governance characteristics that cover the key issues of: (1) stakeholders and governance level; (2) decision support tools and mitigation measures; and (3) stakeholder cooperation and communication. The results provide an overview of the similarities and differences as well as the strengths and weaknesses of the governance systems across risks. Both case studies have developed adequate decision support tools for most of the hazards of concern. Warning systems, and the assessment of hazards and exposure are the main strengths. While technical/scientific capacities are very well developed, the main weaknesses involve the interagency communication and cooperation, and the use and dissemination of scientific knowledge when developing policies and practices. The consequences for multi-risk governance are outlined in the discussion.

Keywords Natural hazard governance - Technical and institutional capacities · Stakeholder cooperation and communication - Qualitative evaluation tool · Comparative analysis

\section{Introduction}

The consequences of disasters in terms of human lives, lost livelihoods and damages are often traced to policies unsuited to the emerging scales of the problems they confront or to the lack of institutional capacity and interagency coordination (Cash et al. 2006; Handmer and Dovers 2007; Peek et al. 2012). One example is Hurricane Katrina, which hit the Gulf coast of the USA at the end of August 2005. The main failures in applying and sharing available information for preventing damage, including the levee break, have been attributed to the lack of effective governance and coordination between elected officials, authorities, and agencies at all levels (De Marchi 2007; Woo 2011). Another example is the 2011 accident at the Fukushima Daiichi power plant in Japan. As reported by the nuclear accident independent investigation committee, the root causes of the disaster were primarily found in "the organizational and regulatory system that supported faulty rationales for decisions and actions" (National Diet of Japan 2012: 16).

In natural hazard research, little attention has been devoted to the study of the governance context of disasters, including the variety of relevant elements ranging from sociopolitical to institutional components.

This paper focuses on these issues, starting from the assumption that technical and institutional capacities should be jointly developed to guarantee effective natural risk governance. Indeed, the available decision support tools influence the development of institutional frameworks and disaster policies. This is true, for example, in case of natural hazard maps which are the starting point when deciding about restrictions to urban growth in risky areas. Also, the institutional architecture may influence the development of the decision support tools, e.g., a centralized risk management system devotes more resources to the development of risk assessments at the national level than a decentralized one (Sharma et al. 2012).

The work presented here is the result of an interdisciplinary research, aimed at describing the technical and institutional characteristics of natural risk governance and at developing a qualitative evaluation tool (Walker et al. 2010, 2013). The logic is that a comparison based on common characteristics can be useful not only to describe governance systems, but also to identify similarities and differences, strengths and weaknesses 
across risks, and, ultimately, to help decision makers identify the main problems, and to set priorities for policy changes across different risk sectors.

The qualitative evaluation tool developed within this work includes three sets of characteristics that cover key issues of: (1) governance actors, level, and scale; (2) decision support tools and mitigation measures (technical capacities); and (3) stakeholder cooperation and communication (institutional capacities).

We analyzed the three sets of characteristics in two real case studies: Naples, a southern Italian city, and Guadeloupe, an archipelago in the northern French West Indies, which comes under the French national and local administrative system. In both case studies, high-intensity natural hazards, such as volcanic and seismic activity, are encountered, as are floods and landslides. Guadeloupe is also prone to cyclones and storm surges and less frequently, to tsunamis, while in Naples, fires are a bigger problem than in Guadeloupe. The two case studies were selected as multi-hazard and multi-risk locations within the context of a broader research project (MATRIX, supported by the European Community's Seventh Framework Programme, see Acknowledgment), which aims to develop new methodologies for multi-hazard and multi-risk assessment for Europe. The latter type of assessment makes it possible to take into account various types of interactions between different risks. Classes of interactions include triggered events, cascade effects, and the rapid increase in vulnerability during successive hazards (see Marzocchi et al. 2012; Garcia-Aristizabal et al. 2013). For example, a volcanic eruption can trigger a landslide or an earthquake can cause a tsunami. We considered Naples and Guadeloupe as valuable case studies for a governance analysis not only because they are exposed to several hazards but also because of the cascade effects-which were analyzed in parallel by conducting multi-risk assessment within the same project (see Garcia-Aristizabal et al. 2013; Monfort and Lecacheux 2013). More precisely, in Naples, two scenarios of interactions between volcanic activity and seismic hazard and risk were conducted. In Guadeloupe the interaction between earthquake and landslide phenomena and its consequences on road networks was assessed.

However, the focus of this paper is on multi-risk governance rather than assessment. Therefore, it is important to mention that both Naples and Guadeloupe have embarked upon several short- and long-term plans to make their citizens safer from natural hazards. Experts in science, engineering, and policy makers are heavily involved in the activities that are aimed at mitigating risk. These practitioners and researchers are the starting point of our research. Indeed, the results presented in the following sections are based on stakeholder judgments, opinions, and evaluations of existing governance systems.

In the future, these results are envisaged to be tested, used, changed, and updated in collaboration with practitioners to provide them with an overview of natural hazard governance and to help them to set out the required actions for policy change across risks. Before presenting the results, however, we will summarize the theoretical and methodological background of the research.

\section{Background}

Interest in governance has undergone a dramatic increase in recent years across a variety of disciplines in which it is applicable, ranging from sociology to political sciences and economy (De Marchi 2003; Renn 2008; IRGC 2009; Walker et al. 2010; Verweij and Thompson 2006). In recent years, definitions and theoretical frameworks have proliferated (e.g., Commission on Global Governance 1995; Rhodes 1996, 1997; UN-ISDR 2005; 
ISDR 2009, 2011; Biermann 2007; IRGC 2008, 2009; Renn 2008; Bevir 2009; van Asselt and Renn 2011; Djalante et al. 2011; Ikeda and Nagasaka 2011). Moreover, it has been applied in very different contexts from the workings of the global stock markets to nanotechnologies, and from genetics to environmental issues (examples of the different interpretations of the term governance can be found in Scolobig et al. 2013). The interest can be ascribed to several reasons, such as the fact that it is a very broad concept; it involves the collaboration of a multiplicity of stakeholders in risk decision making; it pertains to formal and informal institutions; and it includes matters of institutional design, technical methodology, administrative consultation, legislative procedure, and social corporate accountability (Bevir and Trentmann 2007; Renn 2008).

Probably also because of this wide spectrum of topics and definitions, there are very different views of what governance is or should be. As a consequence, analytical lenses can be empirically rooted on different aspects, e.g., governance as problem solving, as the result of competing values and interests among the stakeholders involved, as institutional interactions or as dealing with structural constraints (Bovens and 't Hart 1996; Jessop 1998, 2003; Kaufmann 1999; Kaufmann et al. 1999; Biesbroek et al. 2013; De Marchi 2013). In our study, we started from the definition provided by the Commission on Global Governance (1995: 2): "Governance is the sum of the many ways individuals and institutions, public and private, manage their common affairs. It is a continuing process through which conflicting or diverse interests may be accommodated and co-operative action may be taken. It includes formal institutions and regimes empowered to enforce compliance, as well as informal arrangements that people and institutions either have agreed to or perceive to be in their interest."

Probably not by chance, the methodologies for governance analysis applied to real case studies are less developed than general theoretical frameworks. In recent years, a number of international projects have sought to measure some aspects of governance quality (for an overview, see Bovaird and Loofler 2003). Some projects have been at the global scale, with others at the national, regional, or local level. Existing methods for governance analysis range from desk studies to questionnaire surveys or qualitative interviews with experts. To cite an example, one successful tool to measure the quality of governance has been developed by the World Bank (Kaufmann et al. 1999). It provides a set of six aggregate indicators based on information and perceptions from public officials, nongovernmental organizations (NGOs), aid donors, and economic actors, etc. The dimensions analyzed included accountability, political stability, absence of violence, government effectiveness, regulatory quality, rule of law, and control of corruption. The indicators chosen for each dimension range from the extent to which citizens are able to participate in selecting their government to the ability of the government to formulate and implement sound policies and regulations.

However, most of these indicators are too general and broad to describe the specific characteristics of natural risk governance, the focus of this paper. There is still no consensus among scholars on the operationalization of risk governance, as it can be clearly concluded after reading the research results on the topic (e.g., van Kersbergen and Van Waarden 2004; Biermann 2010; Bodin and Crona 2009; Memon et al. 2011; Benn et al. 2009; Linke and Jentoft 2012; Assmuth et al. 2010; Fish et al. 2010; Boholm et al. 2012). In comparison with other sectors, risk governance tries to overcome the strict division between institutional and technical aspects of risk issues. It does this by assuming that risks are multidimensional and that responses to them should be integrated and grounded on interdisciplinary work and cooperation (Beck 1992; Luhmann 1990; Assmuth et al. 2010; Biermann 2007). 
This is particularly true for natural hazard governance that traditionally involves the activities of numerous stakeholders, such as public and private services, voluntary, and community organizations, in the different phases of the disaster cycle, from risk assessment and prevention to early warning, monitoring, emergency management, reconstruction, and communication (e.g., IRGC 2008, 2009; Walker et al. 2010; Beniston et al. 2011; Dieperink et al. 2013).

To our knowledge, there are few examples of comparisons across natural risks (and countries) that are grounded on common sets of characteristics (Kuhlicke et al. 2012; Walker et al. 2013). For example, Walker et al. (2013) provide a qualitative risk-profiling tool enabling eight characteristics to be taken into account, i.e., policy framework, regional institutions, municipal role, public risk communication, culture of multi-stakeholder participation, segmented or marketized insurance, responsibility on those at risk to protect themselves, and maintaining a good balance between governance tasks and resources. In this way, they compare, for example, the governance of river flooding in Austria and the UK, by providing a visual representation of the different characteristics. The research of Walker et al. (Walker et al. 2013) was one of the key starting points for this study, although we developed the comparison in a different way.

Rather than eight characteristics, we identified three sets of characteristics, for a total of 14 (see chapt. 4). Probably the most relevant difference is the inclusion of stakeholder mapping as well as technical capacities, i.e., a set of characteristics describing decision support tools and mitigation measures, which provides information on the science-based governance tools developed by public agencies or private consultants for public use. We include this set because we consider technical and institutional capacities as complementary aspects to describe governance. Another difference regards the characteristics' evaluation. The governance profile provided by Walker et al. is "inherently qualitative and judgmental in character, subject to the perspective and evaluation of the person creating the profile" (Walker et al. 2013: 2209). We provide instead qualitative evaluations on a 1-7 Likert's scale based on iterative rounds of stakeholders' interviews and not on the evaluation of one single external observer, i.e., a researcher. The use of the Likert's scale for the evaluations allowed us to better represent the key differences across risks and countries and to identify the main strengths and weaknesses of risk governance systems. We will describe these aspects in greater depth in the following sections (see chapt. 4 and 5).

\section{Research design and study sites}

\subsection{Research design}

The research design included a documentary analysis to provide a description of the institutional, political, and legal framework for natural risk governance in the case studies. More precisely, we performed an analysis of the legal, regulatory, and policy documents at national, regional, and municipal levels for each natural hazard under study in Naples and in Guadeloupe. This analysis was complemented by a review of available reports, academic papers, journalist commentaries, and even Web sites. This provided a description of the natural risk governance systems in each of the two case studies for multiple hazards, including earthquakes, volcanic eruptions, landslides, floods, tsunamis, fires, cyclones, and marine inundations (see Scolobig et al. 2013).

In parallel, we conducted a literature review on risk governance focused on existing theories, methods, criteria, and tools to analyze it. We identified one research gap in the 
lack of characteristics to compare governance across risks and countries. Therefore, we elaborated some hypotheses about these characteristics and validated them through stakeholders' interviews.

We conducted a total of 32 semi-structured interviews in different rounds. The interviews were conducted with different stakeholders, e.g. officers and directors of civil protection, fire brigades, urban planners, directors of research institutes, university professors, members of NGOs in the environmental protection field, risk and emergency managers working at different levels (from national to local) and in the diverse natural hazard contexts (earthquakes, landslides, etc.). In a first round of interviews, we identified three sets of governance characteristics and asked interviewees to provide feedback on them and to discuss strengths and weaknesses of the present risk governance systems. The process of refinement and identification of these characteristics included several iterations. From a preliminary list of more than 30 characteristics, we selected 14, divided between the three sets described above (see chapters 2 and 4). In the selection process, we had to take into account a number of constraints such as data availability, data reliability, crosscountry comparison, and cross-hazard comparison. For example, information on economic resources deployed for risk management of the numerous natural hazards under study was not always available, even if this is beyond doubt a key aspect. Also the differences in the regulatory and institutional frameworks in Italy and France ${ }^{1}$ did not allow for the provision of comparable characteristics related, for example, to the disaster risk phases.

In a second round of interviews, we asked interviewees to provide evaluations for each characteristic on a Likert's scale from 1 (min) to 7 (max). We stopped the round of interviews when the evaluations of the stakeholders converged to the same values (see Sect. 4). A numerical evaluation allowed us to better ground our discussion on the strengths and weaknesses of the present governance systems. However, it is important to emphasize that these evaluations are meant to provide a qualitative, flexible, and dynamic tool to foster discussion with interviewees rather than to provide a static description of reality.

The preliminary results were discussed and challenged during focus group discussions with experts and researchers with experience in natural hazard management (an extended research report describing the research design in greater depth is available: Scolobig et al. 2013).

\subsection{Study sites}

Naples (population 962,000, National Census, 2011) is the biggest municipality in southern Italy and the capital of Campania, one of Italy's 20 regions. The city has a widely recognized high volcanic hazard and is also exposed to earthquakes, floods, landslides, and fires. Most of these risks are interconnected. Earthquakes from both the tectonic seismic source (Apennine chain) and volcanic sources (Campi Flegrei and Somma-Vesuvio) can be felt in Naples. Flood events are also very frequent because of the Mediterranean climate and the geomorphology of the city, which lies mainly on narrow coastal plains bordered by pyroclastic hills, and whose slopes speed up the flow of sediment-laden waters toward the sea (Alberico et al. 2011). In the last few years, severe forest fires have also been reported in the city, mainly during the summer period: For example, more than 40 human-made fires

\footnotetext{
${ }^{1}$ In Italy, the phases are risk assessment and prevention; monitoring, early warning and prediction; emergency management and relief; recovery and reconstruction. In France, the phases are hazard assessment; prevention/preparedness; monitoring; advice on alert; alert; crisis management.
} 
affecting the green areas of the city were registered in 2011 (Dipartimento risorse agricole 2012). Forest fires can be caused by another threat to the city: the Somma-Vesuvio and Campi Flegrei volcanic sources. The volcanic risk is high because of the combination of the high population density and of the number of buildings exposed to this explosive and eruptive hazard, which, should pyroclastic clouds occur, would have immense destructive power.

The French overseas department of Guadeloupe (Département-Région d'Outre Mer) is exposed to similar types of hazards, although with different characteristics. In contrast to Naples, it is also prone to cyclones and less exposed to fires since the archipelago has a tropical climate. Guadeloupe is located in the Lesser Antilles and includes five main Islands (Grande-Terre, Basse-Terre, Marie-Galante, la Désirade, and Les Saintes) covering an area of $1,628 \mathrm{~km}^{2}$. The archipelago has 32 municipalities. The major geological risk in Guadeloupe is the active volcano of la Soufrière and seismic activity along the inner Caribbean arc. Tsunamis and landslides can be triggered by those hazards. The main meteorological risk is due to its high exposure to cyclones (hurricane) and tropical storms. Guadeloupe can be directly impacted by very high winds (up to $200 \mathrm{~km} / \mathrm{h}$ ) and/ or rainfall with secondary effects of sea water surges, waves, and marine floods that can erode the coastal zone, and also heavy rainfall which often leads to inland floods and landslides.

\section{Results}

In this section, we present the results of the qualitative evaluation of natural risk governance in Naples and Guadeloupe. On the basis of the documentary analysis and interviews, we have identified three sets of governance characteristics:

1. Stakeholders and governance level: this includes a description of the diverse and interdependent set of stakeholders involved in the natural risk governance system, their roles and responsibilities. These stakeholders typically work at different levels, and we considered the national, regional/river basin, and municipal level. This set thus provides information on the institutional architecture;

2. Decision support tools and mitigation measures (technical capacities): hazard, exposure and vulnerability maps, monitoring and warning systems, emergency plans, and risk mitigation measures were considered. As a result, this set provides information on the science-based governance tools developed by public agencies or private consultants for public use;

3. Stakeholder cooperation and communication (institutional capacities): this includes information related to the cooperation and exchange of knowledge among actors, as well as their involvement in risk decision-making processes. It covers a wide range of issues, including public availability of hazard/risk assessments, planning integration at different levels, the balance between governance tasks and resources, multi-stakeholder participation, responsibility on those at risk for protection. As a result, this set provides information about the interactions between the science and practice domain.

\subsection{Stakeholders and governance level}

In Italy and France, private and public stakeholders from the national to the municipal level interact to guarantee an effective governance system (Figs. 1, 2). Several ministries have 
the responsibility for the development of legislation, guidelines, policies, and the coordination of other agencies for natural risk management. In Italy, there is a mixed top-down, bottom-up organizational system (OECD 2009). The 20 Italian regions also have legislative powers for natural hazard management, a result of the devolution and decentralization process that started in 1998 (Bassanini Law Decree 1998; Constitutional Law 3/2001). In France, risk management has a more centralized/top-down nature, with a strong role played by the state authorities (either central or local representatives, i.e., prefect and state representation of the ministries for Environment and Equipment). However, regions and departments have no regulation competency for risk management.

In Italy, the department of civil protection is a national coordinating body and works together with the competence and functional centers (law decree 3593/2011). These centers are institutions that provide scientific and technical expertise about the nature of hazards and risks, the vulnerability of the population and assets, monitoring and real-time predictions and the development of mitigation measures. Another key actor is the civil protection service (established by law 225/1992, last update law 100/2012), an umbrella institution which guarantees the coordination of disaster management activities. Its main operational organizations are the fire brigades, army, police forces, forestry service, the national health service, voluntary organizations, etc. Relevant members are also the mayors, the prefects, and the presidents of the regional councils. The guiding principle for emergency management in Italy is subsidiarity. When municipal government capacities are insufficient for managing the scale of an event, they are supported by provinces and regions or the state, depending on what kind of event it is. When a disaster happens, also municipal and/or provincial, regional, and national operations centers (MOCs) are activated. Local emergency units work together to define the intervention strategy (Citta' della Scienza 2008; Regione Campania 2008).

In France, there is a similar emergency organization (law 2004-811 from August 13, 2004). The mayors are the main actors responsible for safety in their respective municipalities. The prefects (state representatives at the department level) are responsible for the

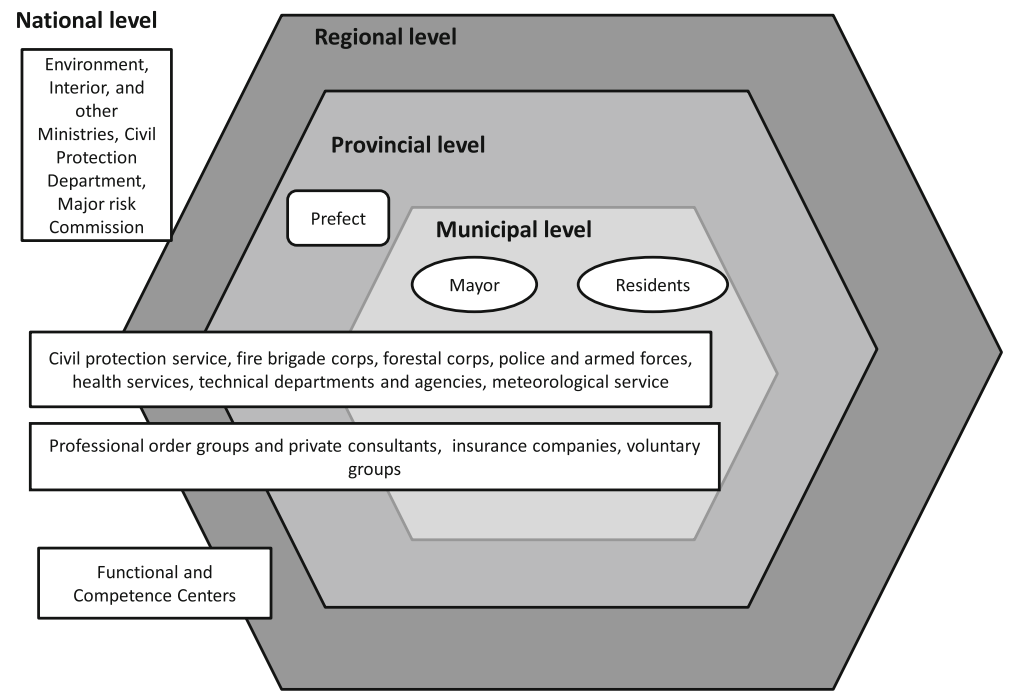

Fig. 1 Main stakeholders in Italy 


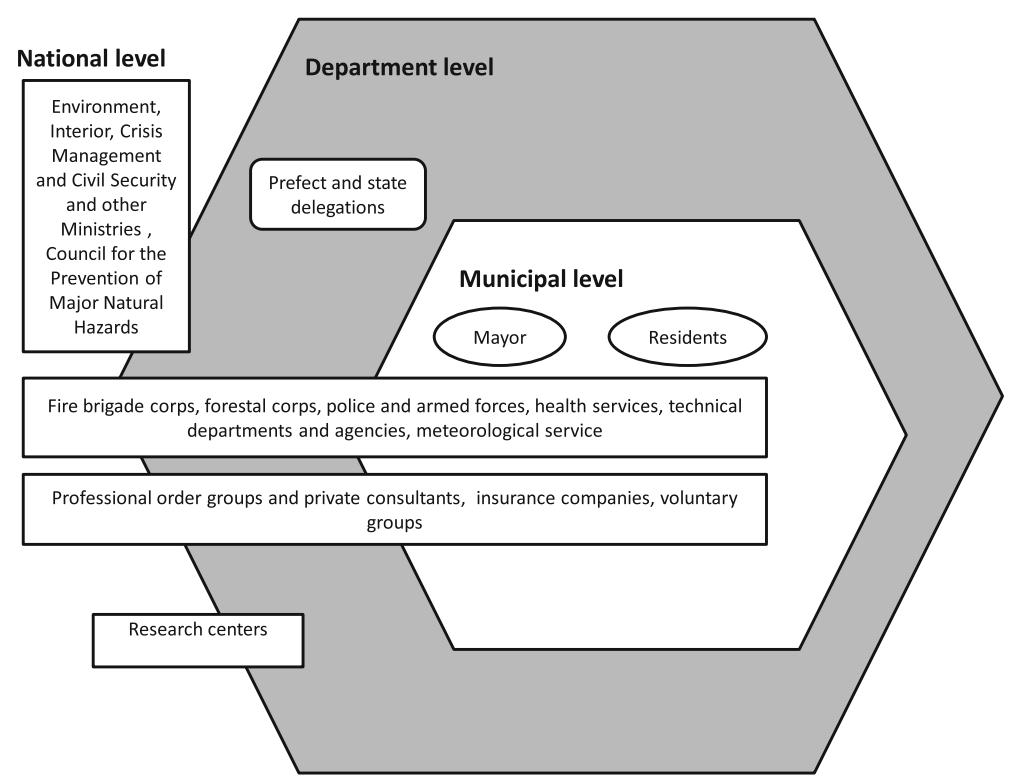

Fig. 2 Main stakeholders in France

local application of policies. They can prescribe the implementation of plans and are to take over the crisis management if a municipality is overwhelmed. Departments and regions can also contribute, mainly by financing equipment or mitigation measures. The risk research and scientific community is made up of several different actors, but they are not organized in networks by law, as is the case of the competence and functional centers in Italy.

Another key difference concerns the insurance sector. In Italy, this is not very developed. Indeed, there is no private insurance available for many natural hazards, for example, landslides and floods. For others, like earthquakes and fires, there is only partial coverage. In particular, earthquake insurance is generally taken out only by industrial plants. This is a consequence of the Italian policy of direct intervention by providing post-disaster financial aid and enacting ad hoc laws for recovery.

The French system on the other hand allows a risk transfer to insurance and to the state. Compulsory insurance on property and homes includes a contribution to a national fund ("fond Barnier," decree 2005-29 from January 12, 2005) which helps indemnify property owners against unexpected and major natural disaster events (CATNAT $=$ catastrophe naturelle) and also supports risk research and risk prevention. Figures 1 and 2 summarize the main stakeholders in Italy and France working at different levels.

\subsubsection{Stakeholder evaluations}

The main authorities in charge of natural hazards and risks management differ between risks. As revealed by the documentary analysis, one of the characteristics that better allows one to grasp these differences is the governance level, i.e., the role played by public authorities at municipal, regional/river basin, and national levels in risk management. 
Based on stakeholder evaluations, Fig. 3 summarizes the role of the public sector (municipal, regional/river basin, and national) for the relevant risks in Naples. ${ }^{2}$

It is not possible here to comment on single risks, so we will focus on the key differences between risks (for a detailed overview, see Scolobig et al. 2013). For example, the management of volcanic risk is highly centralized, with the national civil protection authorities having a leading role and almost exclusive responsibility for it, together with the National Institute of Geophysics and Volcanology (INGV). For hydrogeological risks (floods and landslides), the structure is more decentralized, with the regional and the river basin authorities playing a key role. To be more precise, the river basin authorities are responsible for flood/landslide hazard and risk assessment and for the production of basin plans, and hazard/risk maps (usually at a scale 1:25,000). The regional authorities are also involved in the fire and seismic risk management, even if for the last one the national authorities play a very relevant role with the preparation of seismic hazard and risk maps. Instead each region has the competence to organize its fire fighting system, including prevention and planning activities. Regional plans for forecast, prevention, and active struggle against forest fires have to elaborate a risk assessment, considering both predisposing factors and causes. In the case of earthquakes, emergency management is supported by two main surveillance seismic networks that rapidly disseminate information about an event as soon as it occurs: the seismometric network of INGV and the National Accelerometric Network (RAN) of the civil protection department. Fire fighting is carried out by ground teams in coordination with the national forest fires air fleet. The unified airborne operations center of the national civil protection is in charge of coordination of request of assistance made by regional systems (for an overview of single risk governance systems, see Scolobig et al. 2013).

In Guadeloupe (Fig. 4), monitoring of the main phenomena is under the responsibility of national observatories networks which have local branches in the archipelago. The volcanological and seismological observatory of Guadeloupe (OVSG), part of the Institut de Physique du Globe-Paris, is in charge of the seismic and the volcanic monitoring, while meteorology is monitored by Meteo France. These institutions both monitor and provide advice to the prefect on what alert level to announce when an event occurs. For floods and landslides, which are considered as secondary hazards, monitoring is much less implemented and the role of municipalities is more relevant.

When asked to identify strengths and weaknesses in the institutional architecture, stakeholders in the two case studies provided very different answers. For example, interviewees in Naples (but not in Guadeloupe) tend to agree that a decentralized system is more conducive to effective risk governance. They maintain that for hydrogeological risks, more information and studies are available and that interagency cooperation at the local level is easier than for other risks. However, a decentralized system also has some limitations related primarily to the lack of funding transfer at the local level.

Interviewees in Guadeloupe, on the other hand, believe that the present system is efficient, with responsibility residing in the prefect and the mayor (the prefect being subsidiary to the mayor in case of failure). The interviewees also stated that much more cooperation is necessary between neighboring islands (whether independent, Montserrat or

\footnotetext{
${ }^{2}$ As mentioned above (see Sect. 4.1), it is important to note that subsidiarity is the guiding principle for emergency management in Italy, but not for hazard, exposure and vulnerability assessment, warning system, or reconstruction and risk mitigation measures. The stakeholders' evaluation concerning the governance level summarize the role of different authorities across disaster phases and are meant to be complementary to the evaluations regarding decision support tools and stakeholder cooperation and coordination.
} 


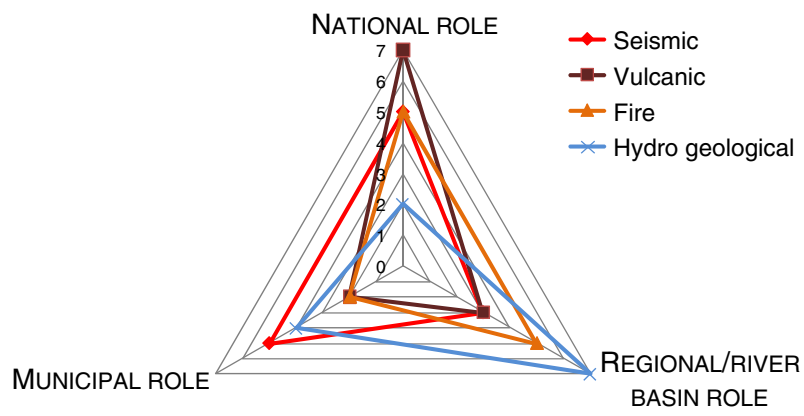

Fig. 3 Role of public sector levels in governance in Naples [evaluation provided on a 1-7 Likert's scale: 1 min role, 7 max role]. ${ }^{*}$ Hydrogeological risk in Naples includes floods and landslides (managed by river basin authorities)

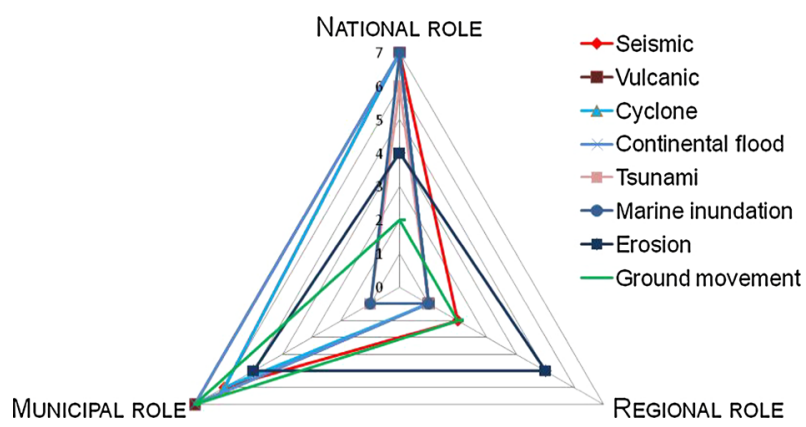

Fig. 4 Role of public sector levels in governance in Guadeloupe [evaluation provided on a 1-7 Likert's scale: 1 min role, 7 max role]

Dominica, or French oversea departments-Martinique). This cooperation should be in terms of the observatory networks, alerts, a common GIS platform, the sharing experiences, etc.

A weakness that hinders effective governance is shown in Italy with respect to the difficulties in cooperation between public agencies working at different levels (e.g., national, regional, and municipal). This is clearly a problem for the management of cascade and conjoint effects. For example, when discussing the scenario about the effects of seismic swarms triggered by volcanic activity in Naples, some difficulties emerged in the interaction between the national authorities in charge volcanic risk and the regional authorities in charge of seismic risk. Authorities at the municipal level should ensure that knowledge available at national and regional level can be used and disseminated locally. However, as we will better describe in the following sections too (see chapt. 5), these authorities very often lack capabilities and resources to do so. Even greater difficulties have been reported for the interactions between the public and private sector. Stakeholders in both case studies suggest that new forms of partnerships within and between the public and private sector need to be developed. 


\subsection{Decision support tools and mitigation measures}

A number of science-based tools are available to support decisions in the various phases of the disaster risk cycle. A key difference between the two case studies concerns hazard, exposure, and vulnerability assessment. While in France, the risk prevention plans (PPR) collect information about each specific hazard (which are then summarized into one map for Guadeloupe), in Italy, tools and maps are prepared by a number of different agencies and authorities. There is therefore no single document available, that combines all risks, or at least it is not compulsory by law.

The PPR in Guadeloupe, as all over France, are a legally binding urban planning document regulating land use and imposing construction rules in risk-prone zones at the municipal level (laws 87-565 from 1987, 95-101 from 1995 and 2003-699). The maps are drawn up for all municipalities of the islands. In Naples, the system is "single riskcentered" with different authorities providing maps and tools for integration into urban planning. The systematic assessment of landslide/flood hazard, risk, and vulnerability is performed by the river basin authorities which provide several plans based on a four level risk classification scheme (Law 183/1989; law 267/1998). With regard to earthquakes, the regions are in charge of the identification, classification, and updating of seismic areas based on a national seismic hazard map produced by the INGV (National Ordinance 3519/2006). Regional plans for forecast, prevention, and forest fire fighting itself have to work out risk assessment, considering both the predisposing factors and causes of the risk. Mapping of the forests is planned at the regional level but implementation is at the local level.

In Italy for predictable events (hydrogeological and volcanic risk), guidelines are available for the establishment of warning systems. These guidelines specify the characteristics of the monitoring systems and the procedures to be applied for each alert level. These guidelines are provided in the national emergency plans for the volcanic risk and in the form of national directives for the hydrogeological risk.

As for the seismic risk, only a prototype system for seismic early and post-event warning is being developed and tested in the Campania region called "Seismic Alert Management System" (SAMS).

In Guadeloupe, when forecasting is possible, institutions charged with monitoring are responsible for advising the prefect who is responsible for announcing the level of alert. This takes place in the event of cyclonic and tropical storm events and volcanic eruptions; alert levels are from yellow to gray and matched with behavioral recommendations for the population, depending on the hazard. For earthquake risk, a post-event intensity maps are produced by the volcanological and seismological observatory of Guadeloupe.

Another key decision support tool is the emergency plan which follows general guidelines provided at the national level in both countries. In Naples, there is an organic and systematic method, the so-called Augustus method, elaborated in national guidelines. From July 2012 (law 100/2012), municipal authorities are legally obliged to set up emergency plans, which collect available information about potential risks and establishes relevant procedures. In Guadeloupe, the Organization for Civil and Security Response (ORSEC) plan is a general plan that describes the emergency organization in case of a disaster where the local means are insufficient, while also defining the actions needed to restore a normal situation. The ORSEC plan in its latest version urges the municipalities to design a safety plan (Plan communal de sauvegarde, PCS), so as to be ready for disastrous events, and to have the means to act in an emergency (information for citizen, evacuation plans, etc.). This safety plan must consider all possible risks and conjoint/cascade effects. 
Finally, under the label of risk mitigation measures, are included all the measures that can be adopted to reduce risk, including structural engineering works in the case of floods and landslides, building code and retrofitting provisions in the case of earthquakes or volcanic risks, forest clearing and maintenance for the case of fire risks, etc. Investments in these measures have been made both in Italy and Guadeloupe.

\subsubsection{Stakeholder evaluations}

This section summarizes stakeholder evaluations regarding decision support tools and mitigation measures. We asked stakeholders to evaluate the availability of these and the territory coverage on a 1 (min: tool/plan not available) to 7 (max: tool/plan available and covering the entire territory) Likert's scale. As Figs. 5 and 6 show, many differences can be identified across hazards and risks.

In Naples (Fig. 5), the main strengths are the hazard assessment and the monitoring/ warning system. This means that hazard maps are available and a monitoring/warning system is in place for all the natural hazards under study. Exposure and vulnerability assessment are also available but with differences depending on the hazard. For example, in the case of fire, vulnerability assessment is sporadically performed by local authorities, in most of the cases in a very qualitative way. The same is partially true for hydrogeological phenomena. In the case of volcanic and seismic risk, vulnerability maps are available for public buildings, while maps for private buildings are also available, even if not always to the general public. Monitoring, forecasting, and hazard/risk assessment for hydrogeological risks are characterized by lower levels of uncertainty in comparison with seismic events. Also inherent to each phenomena's temporal/spatial scale, the methodological approaches for hazard and risk assessment are very different: For example, seismic vulnerability assessment is based on maps and on the physical vulnerability of individual households, while hydrogeological risk assessment is based on spatialization of hazard and risk maps (often at a scale 1:25,000) as well as event modeling and simulations.

The main weaknesses are related to emergency planning and risk mitigation measures. For volcanic risk, there is an emergency plan prepared and constantly updated by the national civil protection in Rome. For the other natural risks, the responsible authorities are at the municipal level, and the emergency plan was in preparation when this research work was performed in Naples in 2010/2011 (i.e., before the enactment of law 100/2012). As reported by the head of the municipal technical office: "One of the key problems in Naples is that it is not possible to identify escape routes that can be used for different purposes and risks. As a consequence, residents need to remember different instructions depending on the type of event and risks." As reported by another interviewee: "In the case of earthquakes, for example, the historical center of the city is highly endangered and it is not possible to identify safe rescue points for the inhabitants" (head of one of the river basin authorities). Avoiding citizen panic is still a major concern for public authorities and the idea of open communication about the lack of escape routes and safe areas worried many interviewees.

With regard to risk mitigation measures, a key problem is the lack of economic resources. Interviewees in Naples report that in the past more resources had been allocated for some risks, particularly for structural protection measures against flash floods and landslides. This may be due to the higher frequency of these events, and also to the fact that structural works protect entire communities, whereas in the case of seismic or volcanic risk mitigation, measures have to be adopted at the household level. At the same time, we have 


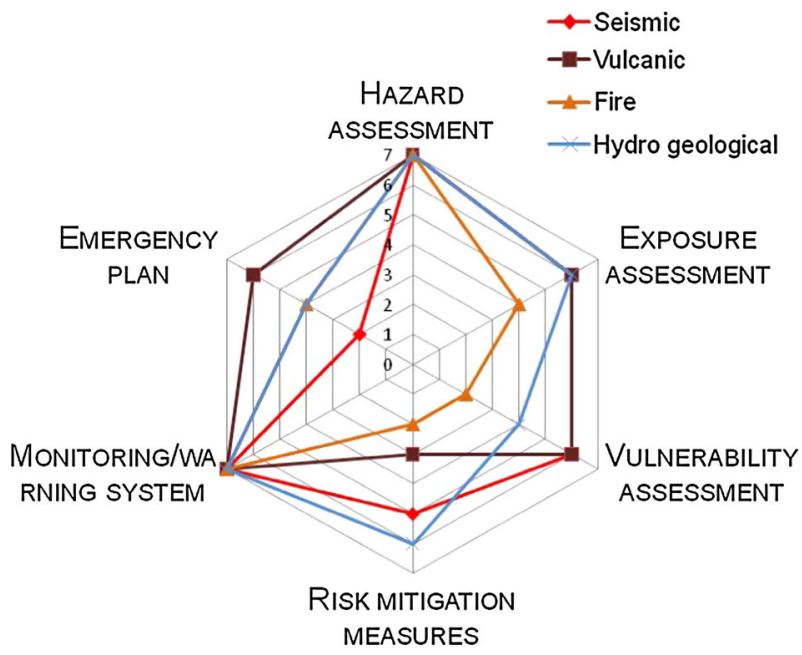

Fig. 5 Decision support tools and mitigation measures in Naples [evaluation provided on a 1-7 Likert's scale: 1 tool/plan not available, 7 max coverage]. *Hydrogeological risk in Naples includes floods and landslides (managed by river basin authorities)

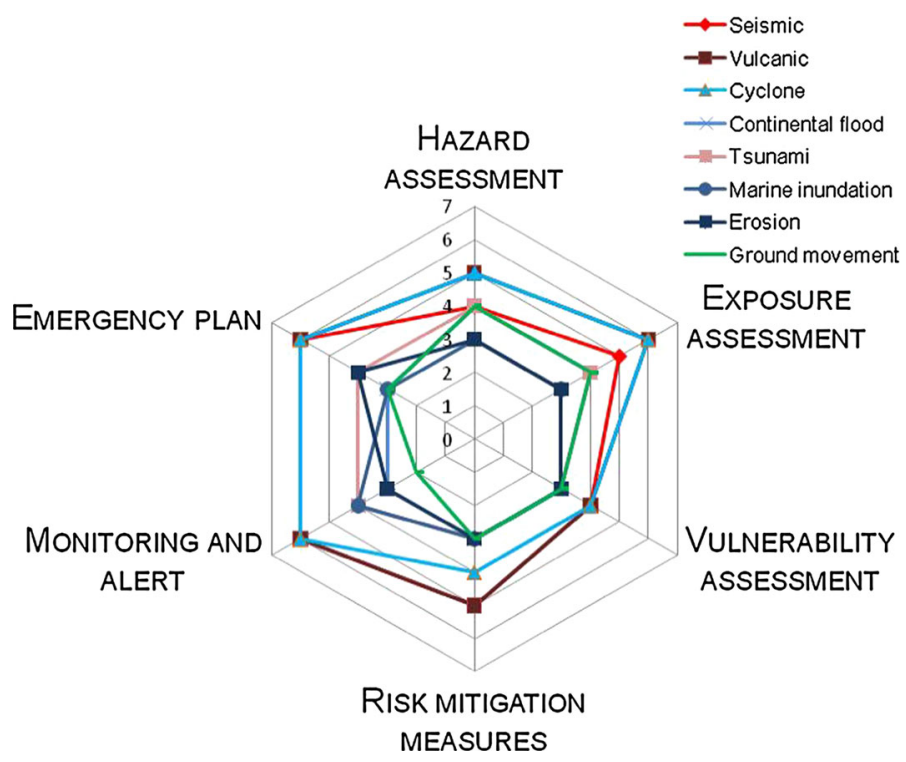

Fig. 6 Decision support tools and mitigation measures in Guadeloupe [evaluation provided on a 1-7 Likert's scale: 1 tool/plan not available, 7 max coverage]

no clear evidence of the economic resources spent on mitigation for each of the risks of concern.

In Guadeloupe (Fig. 6), the PPR are said to be multi-hazard. However, as reported by interviewees, PPR have mainly been elaborated for single risks (volcanic, earthquakes, landslides, and floods), and then compiled into a synthetic map. The links between hazards, 
such as triggering effects, are not considered, and recommendations are drawn up for individual risks; a practice that could lead to dangerous side-effects. For example, a concrete roof that, while resistant to cyclone force winds, could be fatal in the case of an earthquake building collapse. As in Naples, hazard and exposure assessment as well as the warning system is the strength of the system when high-intensity hazards such as cyclones, earthquakes, and volcanic eruptions are considered. Vulnerability assessments, as described by the interviewees, give priority to population security. However, the lack of knowledge of the other dimensions of vulnerability leads to inadequate mitigation measures. The profile for Guadeloupe also underlines the lack of available knowledge and, therefore, inadequacies in the management of moderate-intensity/high-frequency hazards such as inland floods and landslides. This can be explained by the fact that these phenomena are localized (in comparison with earthquakes or cyclones which are widespread).

\subsection{Stakeholder cooperation and communication}

This set represents some relevant institutional capacities for natural risk governance, including a number of characteristics focused, for example, on the integration of different types of plans, on institutional fits and misfits across spatial and temporal scales and different sectors, on the involvement of stakeholders in decision making, etc. In comparison with the other sets of characteristics, these ones are less tangible and, in general, there are fewer legislative requirements and obligations regarding cooperation and communication issues.

\subsubsection{Stakeholder evaluations}

Figure 7 summarizes the main results about the science-governance interactions in Naples, again on a 1-7 point Likert's scale. Hazard, exposure, and vulnerability assessment are in general publicly available and accessible online, even though there is no Web site including all this information for different risks in a consistent way. For example, hydrogeological assessments are available on the river basin authorities' Web sites, while the seismic maps are available on the INGV Web site. Yet, the question is do the residents of Naples know that there are different authorities in charge of the assessments of different risks? How much are these online assessments consulted and how user-friendly are they?

Effective communication is the foundation to building a culture of multi-stakeholder participation. The latter is, in general, quite weak. Hydrogeological risk is likely to improve, due to the implementation of the EC Flood Directive (Directive 2007/60/EC), which aims at the wider stakeholder involvement in river basin management (Fig. 7).

With regards to the integration of decision support tools in existing urban planning, some interviewees maintain that there is a need to harmonize risk assessment for different risks in order to guarantee a better identification of priorities for risk prevention and mitigation. This is also clearly linked to the development of multi-hazard and riskassessment methodologies that could help provide a better integration of the present decision support tools in existing urban plans. Integration requires human resources and time: the imbalance between governance tasks and resources seems to be a major constraint. It is interesting to note that this imbalance is stronger for those risks (seismic and volcanic) characterized by a higher level of responsibility on those at risk for protection. Household mitigation measures are the responsibility of homeowners in the case of seismic, volcanic, and hydrogeological risk. There is no legislative obligation, excluding the need for new buildings to respect the various building and planning codes established by 


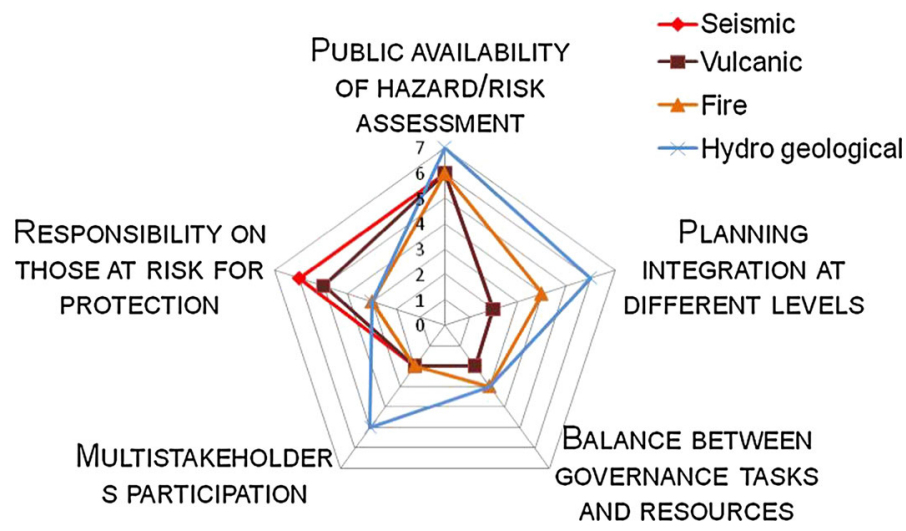

Fig. 7 Stakeholder cooperation and communication in Naples [evaluation provided on 1-7 Likert's scale: 1 min, 7 max]. *Hydrogeological risk in Naples includes floods and landslides (managed by river basin authorities)

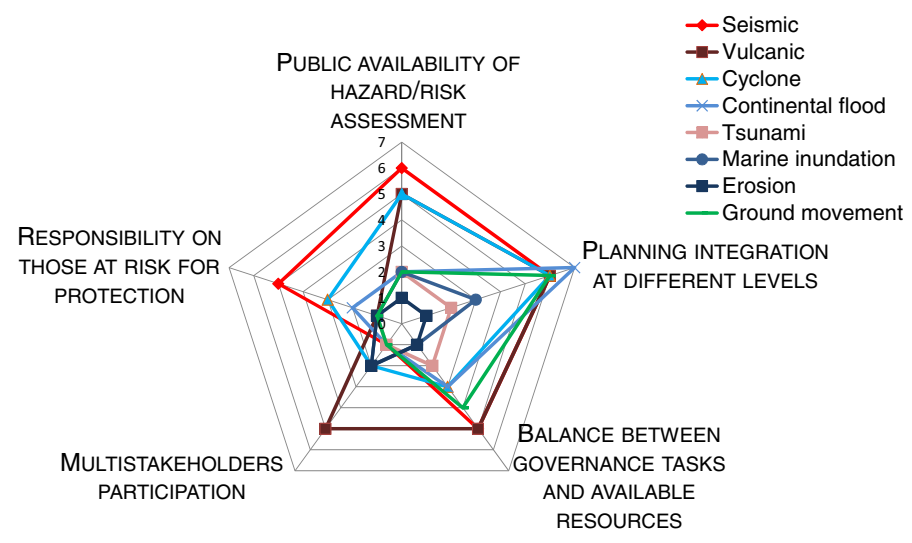

Fig. 8 Stakeholder cooperation and communication in Guadeloupe [evaluation provided on 1-7 Likert's scale: 1 min, 7 max]

law. Most of the time, resources are insufficient or household risk mitigation measures are too expensive.

In Guadeloupe (Fig. 8), public authorities in charge of risk and emergency management are more focused on education campaigns in the field than public access to technical documents. They also believe that the local population is aware of seismic risk and cyclonic winds, probably because of recent experiences of this type of event and the awareness campaigns for seismic risk in schools. The same is not true for landslides and inland floods, whether triggered by the other hazards or not.

This shows how an investment in risk communication and education strategies seems necessary, especially to increase residents' risk awareness and preparedness.

The integration of decision support tools in urban planning seems to work well, probably also because of the existence of the PPR (see Sect. 4.2). Yet, as reported by urban city planners, there is still room for improvement in terms of mainstreaming and 
integrating risks into development policies, strategies, and actions, and, more in general, into urban environmental management and policies. With regard to the balance between governance tasks and available resources, the CATNAT insurance system (see Sect. 4.1) covers natural disasters (after proper evaluation) and is likely to lead to a transfer of responsibility from individuals to the decision makers. However, it is important to bear in mind the specificity of Guadeloupe, which-as one of the French territories-has less insurance penetration than the rest of France.

Finally, the culture of multi-stakeholder participation, i.e., the involvement of public and private actors in risk decision making, is in general quite weak in Guadeloupe. The results point to the dichotomy between high-intensity/low-frequency versus low- to moderate-intensity/high-frequency risk: the profile underlines once again the lack of stakeholder participation in considering low- to moderate-intensity/high-frequency hazards such as inland floods and landslides.

\section{Discussion}

Good governance is identified as being particularly important for reducing risks, for dealing with emergencies and disasters effectively, for supporting actions at several levels from local to international, and for fostering an integrated approach to risk reduction in policies, planning, and programs related to sustainable development. However, the methodologies for governance analysis applied to real case studies are less developed than general theoretical frameworks.

In our research, we conceptualized natural hazard governance as concerned with definable and comparable sets of technical and institutional characteristics that enable risks to be handled in society (see also Walker et al. 2013). The three sets of characteristics used to compare the governance of different natural hazards allowed us to identify similarities and differences across countries as well as strengths and weaknesses of the current systems. The aim of the research was therefore twofold: (1) to cover a methodological gap in natural hazard governance research and (2) to provide a good starting point for practitioners to discuss problems, and priorities for institutional policy changes within multi-risk contexts. The three sets of characteristics provide a wide array of results, which can be commented upon and used for different purposes.

First, the results allow the identification of key similarities and differences in the governance systems in Italy and France. For example, the legislative power at the regional level, the role of the civil protection service, and the networks of competence and functional centers are Italian specificities. A well-developed insurance system (in association with government regulations on CATNAT) and an integrated approach to risk assessment (PPR ) make the difference in the French system. The organization and structure of the warning systems and emergency management are not very different, with the exception of the key role played by the prefects in Guadeloupe.

Second, the results allow the identification of strengths and weaknesses of risk governance across risks and countries, as summarized in Table 1. This table is based on the key results of the interviews and the sum of the evaluations provided by the stakeholders. It is meant to be a qualitative, flexible, and dynamic tool providing an overview that can be used in several potential settings to foster discussion (single risk specificities are instead summarized in Table 2).

For example in Naples, there is a lack of capability at the municipal level. As emphasized by many interviewees, the investment of more resources at this level is 
Table 1 Most relevant strengths (+) and weaknesses (-) in the two case studies

\begin{tabular}{|c|c|c|c|}
\hline \multirow[t]{2}{*}{ Sets } & \multirow[t]{2}{*}{ Characteristics } & \multicolumn{2}{|c|}{$\begin{array}{l}\text { Strength }(+) / \\
\text { weakness }(-)\end{array}$} \\
\hline & & Naples & Guadeloupe \\
\hline \multirow[t]{3}{*}{ Stakeholders and governance level } & National role & & + \\
\hline & Regional/river basin role & & \\
\hline & Municipal role & - & + \\
\hline \multirow{6}{*}{$\begin{array}{l}\text { Decision support tools and mitigation } \\
\text { measures }\end{array}$} & Hazard assessment & + & \\
\hline & Exposure assessment & + & + \\
\hline & Vulnerability assessment & & - \\
\hline & Risk mitigation measures & - & \\
\hline & Monitoring/warning system & + & + \\
\hline & Emergency plan & - & + \\
\hline \multirow[t]{5}{*}{$\begin{array}{l}\text { Stakeholder cooperation and } \\
\text { communication }\end{array}$} & $\begin{array}{l}\text { Public availability of hazard/risk } \\
\text { assessment }\end{array}$ & + & \\
\hline & Planning integration at different levels & & + \\
\hline & $\begin{array}{l}\text { Balance between governance tasks and } \\
\text { resources }\end{array}$ & - & \\
\hline & Multi-stakeholders participation & - & - \\
\hline & $\begin{array}{l}\text { Responsibility on those at risk for } \\
\text { protection }\end{array}$ & & - \\
\hline
\end{tabular}

Note If no sign (+ or - ) is reported, it means that the characteristic has not been evaluated as a relevant strength or weakness, i.e., it received very high or very low evaluations

definitely a priority, so that knowledge available at, for instance, the national and regional levels can profitably be used and disseminated locally. Within the science domain, hazard assessment, exposure assessment, and monitoring/warning systems are well advanced. Greater efforts are needed instead to implement risk mitigation measures and integrated emergency planning. Integrated tools for hazard/exposure assessment (as with the PPR developed for Guadeloupe) can also be considered as good practices to be encouraged in Naples. In Guadeloupe, decision support tools are well advanced but difficulties have been identified in integrating and understanding vulnerability assessments over physical, economic, and social dimensions. With regard to the responsibility on those at risk for protection, the CATNAT insurance system mentioned above covers natural disasters but is likely to lead to a transfer of responsibility from individuals to decision makers. However, it is also important to bear in mind the specificity of Guadeloupe, as one of the French territories with less insurance penetration than the rest of France (Calvet and GrislainLetremy 2011; Monfort et al. 2013). A main common finding is that the set of characteristics related to institutional capacities/stakeholders cooperation and communication have been evaluated, in general, to be much lower than the technical aspects and decision support tools.

Differences across natural hazards are also striking, as summarized in Table 2.

For example in Naples, stakeholder communication and cooperation for hydrogeological risk is, in general, a strength, probably also due to the decentralized system and the role played by the river basin authorities, as boundary organizations. However, the divide between geological (seismic and volcanic risk) and hydrogeological hazards emerges quite clearly in Naples, whereas in Guadeloupe, the divide between high-intensity/low- 
Table 2 Most relevant strengths $(+)$ and weaknesses $(-)$ for different natural hazards $[N$ Naples, $G$ Guadeloupe]

\begin{tabular}{|c|c|c|c|}
\hline \multirow{2}{*}{$\begin{array}{l}\text { Natural } \\
\text { hazards }\end{array}$} & & \multicolumn{2}{|l|}{ Sets of characteristics } \\
\hline & & $\begin{array}{l}\text { Decision support } \\
\text { tools and mitigation } \\
\text { measures }\end{array}$ & $\begin{array}{l}\text { Stakeholder } \\
\text { cooperation } \\
\text { and communication }\end{array}$ \\
\hline \multirow[t]{2}{*}{ Seismic risk } & $\mathrm{N}$ & + & \\
\hline & $\mathrm{G}$ & + & + \\
\hline \multirow[t]{2}{*}{ Volcanic risk } & $\mathrm{N}$ & + & \\
\hline & G & + & \\
\hline \multirow[t]{2}{*}{ Hydrogeological risk } & $\mathrm{N}$ & + & + \\
\hline & G & & \\
\hline Fires & $\mathrm{N}$ & - & \\
\hline Cyclone & $\mathrm{G}$ & + & \\
\hline Continental flood & G & & \\
\hline Tsunami & G & & - \\
\hline Marine inundation & G & - & - \\
\hline Erosion & G & - & - \\
\hline Ground movement & G & - & \\
\hline
\end{tabular}

Note 1 If no sign ( + or - ) is reported, it means that the characteristic has not received very high or very low evaluations

Note $2 \mathrm{We}$ did not include the set of characteristics related to the stakeholders and governance level because they can not be considered "per se" strengths or weaknesses

frequency versus low-intensity/high-frequency risks is more important. For Guadeloupe, this possibly manifests itself by being better decision support tools and stakeholder cooperation and communication for seismic, volcanic, and cyclonic risk than for marine inundation, erosion, or ground movement. Thus, low-intensity/high-frequency events should be considered as a priority on which to focus additional attention.

Our study also has some limitations. One of the main ones is that it only considered two case studies. In both of them, the (possible) occurrence of high-intensity/low-return period events have probably helped to build a higher risk awareness (for these events) than in other regions exposed to multiple hazards. ${ }^{3}$ This clearly poses the question of wider crosscountry comparisons. The differences between countries and risks are definitely more prominent than we expected at the beginning of this work and it suggests the need for more empirical testing.

Another limitation is methodological and concerns the distinction between the descriptive-analytical ("how governance is") and the normative-prescriptive level ("how governance should be,") especially considering the existing legislation and regulatory framework. A very delicate part was the gap between legislation and its implementation, especially where new legislation was concerned. For example, the culture of multistakeholder participation for landslides and floods risk management has been definitely boosted by the implementation of the flood directive (Directive 2007/60/EC), but its

\footnotetext{
${ }^{3}$ In this distinction, it is included a geographical dimension for the Guadeloupe case: high-intensity events as earthquakes, volcano eruptions or cyclones impacts a huge part of the territory in contrast to moderateintensity/high-frequency events like landslides, which are in general more local.
} 
implementation within national legislative frameworks is still in progress. Another example is urban development in risky areas: Even if this is strictly prohibited by law, illegal buildings in high-risk areas are still constructed. However, opinions of experts and local authorizes differ considerably on a number of points, including the extent and scope of illegal buildings (e.g., some attribute the main causes to lack of trust in local authorities, others to lack of information, or lack of control by local authorities), how it has developed, how it can be effectively monitored and by whom, and even what defines illegal development (see De Marchi and Scolobig 2009).

Another methodological limitation regards the evaluations of the different hazards characteristics. In our cases, the evaluations of stakeholders tended to converge and we reiterated interviews to obtain reliable results. However, in the future research, stakeholders' divergent opinions could lead to higher levels of uncertainty during the scoring process. To avoid this shortcoming in the future, questionnaire surveys can be developed in order to obtain data amenable to statistical treatment.

In conclusion, differences across risks and countries are striking and it is difficult to identify common findings. Probably the strongest one is that both countries have developed adequate decision support tools for most of the hazards, but the same is not true for interagency cooperation and communication, thus including how the scientific knowledge feedbacks into the policy and practice domain. This suggests the need to invest more time and resources to better understanding how the development of technical solutions influences the institutional practices for risk management, with a focus on the barriers related to the development of institutional capacities and the use of scientific knowledge in the policy domain. For the aspects related to multi-risk governance, thus including cascade and conjoint effects, institutional arenas with an interdisciplinary and multi-sector character for discussing and acting on multi-risk issues should be created in order to overcome the barriers in interagency cooperation and communication.

As maintained by the practitioners involved in our research, the results proved useful to foster further discussion about future changes to make natural risk governance more effective at the local level. As researchers, we hope that the results can represent a useful step to foster the theoretical and methodological debate on natural hazard governance.

Acknowledgments The work described in this paper was supported by the European Community's Seventh Framework Programme through the MATRIX project-New methodologies for multi-hazard and multi-risk assessment methods for Europe [FP7/2007-2013] under Grant Agreement No 265138. The paper reflects the authors' views and not those of the European Community. Neither the European Community nor any member of the MATRIX Consortium is liable for any use of the information in this paper. We wish to thank all the colleagues and persons who provided us with professional advice and collaboration. We are grateful to all of them and especially to the interviewees who spent their precious time discussing with us the complex architecture of risk governance in Naples and Guadeloupe. We also thank Kathryn Platzer (International Institute of Applied Systems Analysis), Kevin Fleming (German Research Center for Geosciences), and the two anonymous reviewers for helping us to further clarify the text.

\section{References}

Alberico I, Petrosino P, Lirer L (2011) Volcanic hazard and risk assessment in a multi-source volcanic area: the example of Naples city (Southern Italy). Nat Hazards Earth Syst Sci 11:1057-1070

Assmuth T, Hilden M, Benighaus C (2010) Integrated risk assessment and risk governance as socio-political phenomena: a synthetic view of the challenges. Sci Total Environ 408:3943-3953

Beck U (1992) Risk society: towards a new modernity. Sage, London 
Beniston M, Stoffel M, Hill M (2011) Impacts of climatic change on water and natural hazards in the Alps: can current water governance cope with future challenges? Examples from the European "ACQWA" project. Environ Sci Policy 14:734-743

Benn S, Dunphy D, Martin A (2009) Governance of environmental risk: new approaches to managing stakeholder involvement. J Environ Manag 90:1567-1575

Bevir M (2009) Key concepts in governance. Sage, London

Bevir M, Trentmann F (2007) Introduction: consumption and citizenship in the new governance. In: Bevir M, Trentmann F (eds) Governance, consumers and citizens: agency and resistance in contemporary politics. Palgrave Macmillan, Basingstoke

Biermann F (2007) Earth system governance as a crosscutting theme of global change research. Global environmental change. Hum Policy Dimens 17:3-4

Biermann F (2010) Earth system governance: a research framework. Int Environ Agreem Polit Law Econ 10:277-298

Biesbroek G, Termeer C, Klostermann J, Kabat P (2013) Analytical lenses on barriers in the governance of climate change adaptation. Mitig Adapt Strateg Glob Change. doi:10.1007/s11027-013-9457-z

Bodin O, Crona B (2009) The role of social networks in natural resource governance: what relational pattern make a difference? Glob Environ Change 19:366-374

Boholm A, Corvellec H, Karlsson M (2012) The practice of risk governance: lessons from the field. J Risk Res 15:1-20

Bovaird T, Loofler E (2003) Evaluating the quality of public governance: indicators, models and methodologies. Int Rev Admin Sci 69:313-328

Bovens M, 't Hart P (1996) Understanding policy fiascoes. Transaction Publishers, New Brunswick

Calvet L, Grislain-Letremy C (2011) L'assurance habitation dans les départements d'Outre-mer: une faible souscription. ÉCONOMIE ET STATISTIQUE No 447, 201157

Cash D, Borck J, Patt A (2006) Countering the 'loading dock' approach to linking science and decision making: a comparative analysis of ENSO forecasting systems. Sci Technol Human Values 31:465-494

Citta' della Scienza (2008) Methodology management of natural disasters, MEDRISK-Mediterranean Risk Management del "PROGRAMME INTERREG III B ARCHIMED"

Commission on global governance (1995) Our global neighborhood. Oxford University Press, Oxford

De Marchi B (2003) Public participation and risk governance. Sci Public Policy 30(3):171-176

De Marchi B (2007) Not just a matter of knowledge. The Katrina debacle. Environ Hazards 7:141-149

De Marchi B (2013) Risk Governance and the integration of scientific and local knowledge. In: Fra Paleo U (ed) Risk Governance. The articulation of hazard, politics and ecology. Springer, Berlin (forthcoming)

De Marchi B, Scolobig A (2009) Dilemmas in land use planning in flood prone areas. In: Samuels P, Huntington S, Allsop W, Harrop J (eds) Flood risk management: research and practice. CRC Press, Taylor and Francis Group, London, p 204

Dieperink C, Green C, Hegger D, Driessen P, Bakker M, Van Rijswick M, Crabbé A (2013) Flood Risk Management in Europe: governance challenges related to flood risk management (report no D1.1.2), STAR-FLOOD Consortium, Utrecht, The Netherlands

Dipartimento risorse agricole (2012) Piano antincendio boschivo. Regione Campania

Directive 2007/60/EC (2007), Directive of the European Parliament and of the Council of 23 October 2007 on the assessment and management of flood risks. Off J Eur Union L288:27-34. http://eur-lex.europa. eu/. Accessed 22 May 2013

Djalante R, Holley C, Thomalla F (2011) Adaptive governance and managing resilience to natural hazards. Int J Disaster Risk Sci 2:1-14

Fish R, Ioris A, Watson N (2010) Integrating water and agriculture management: collaborative governance for a complex policy problem. Sci Total Environ 408:5623-5630

Garcia-Aristizabal, A, Marzocchi W, Di Ruocco A (2013) Probabilistic framework for multi-hazard assessment. Deliverable 3.4, Matrix project, New methodologies for multi-hazard and multi-risk assessment methods for Europe, European Commission 7th Framework Programme

Handmer J, Dovers S (2007) Handbook of disaster and emergency policies and institutions. Earthscan, London

Ikeda S, Nagasaka T (2011) An emergent framework of disaster risk governance towards innovating coping capability for reducing disaster risks in local communities. Int J Disaster Risk Sci 2:1-9

IRGC International Risk Governance Council (2008) An introduction to the risk governance framework. IRGC, Geneva

IRGC International Risk Governance Council (2009) Risk governance deficits: an analysis and illustration of the most common deficits in risk governance. IRGC, Geneva

ISDR International Strategy for Disaster Reduction (2009) Global Assessment Review 2009. ISDR, Geneva ISDR International Strategy for Disaster Reduction (2011) Global Assessment Review 2011. ISDR, Geneva 
Jessop B (1998) The rising of governance and the risks of failure: the case of economic development. Int Soc Sci J 50:44-45

Jessop B (2003) Governance and metagovernance: on reflexivity, requisite variety, and requisite irony. In: Bang HP (ed) Governance as social and political communication. Manchester University Press, Manchester, pp 101-116

Kaufmann D (1999) Governance matters. World Bank Policy Research Working Paper 2196. Washington, DC

Kaufmann D, Kraay A, Ziodo-Lobaton P (1999) Aggregating governance indicators. World Bank Policy Research Working Paper 2195. Washington, DC

Kuhlicke C, Steinführer A, Begg C, Luther J, Tapsell S, McCarthy S, Walker G, Supramaniam M, Di Masso M, Scolobig A, Komac B, Bianchizza C, Lemkow L, Pellizzoni L, Zorn M, Buchecker M, Brundl M, Wachinger G, Renn O (2012) Toward more resilient societies in the field of natural hazards: lessons learnt in the CapHaz-Net project. http://caphaz-net.org/outcomesresults/CapHazNet_De1\%2010.3_ final.pdf. Accessed 22 May 2013

Linke S, Jentoft S (2012) A communicative turnaround: shifting the burden of proof in European fisheries governance. Mar Policy. 10.1016/j.marpol.2012.04.011

Luhmann N (1990) Risiko und Gefahr. Springer, Munchen

Marzocchi W, Garcia-Aristizabal A, Gasparini P, Mastellone M, Di Ruocco A (2012) Basic principles of multi-risk assessment: a case study in Italy. Nat Hazards 62:551-573

Memon P, Kirk N, Selsky J (2011) Limits to ecological modernization as a framework for sustainable fresh water governance. Land Use Policy 28:534-541

Monfort D, Lecacheux S (2013) West Indies test site. Deliverable 3.4, Matrix project, New methodologies for multi-hazard and multi-risk assessment methods for Europe, European Commission 7th Framework Programme Technical Report D7.4, MATRIX project

Monfort D, Réveillère A, Lecacheux S, Muller H, Grisanti L, Baills A, Bertil D, Sedan O, Tinard P (2013) Observed and estimated economic losses in Guadeloupe (French Antilles) after Les Saintes Earthquake (2004) Application to risk comparison EGU General Assembly 2013, Vienna Austria

National Diet of Japan (2012) The official report of the Fukushima Nuclear Accident Independent Investigation Commission. National Diet of Japan

OECD, Organisation for Economic Cooperation and Development (2009) International futures project on risk management policies, Review of the national Civil Protection System (Italy). OECD publishing. http://www.oecd.org/publishing/corrigenda. Accessed 22 Aug 2010

Peek et al (2012) Understanding the global earthquake model (GEM's) potential beneficiaries: a study of earthquake risk reduction activities, needs and barriers. Research report, Pavia, Italy, GEM foundation

Regione Campania (2008) Identification of natural and man made induced disasters, MEDRISK-Mediterranean Risk Management "PROGRAMME INTERREG III B ARCHIMED"

Renn O (2008) Risk governance. Coping with uncertainty in a complex world. Earthscan, London

Rhodes R (1996) The new governance: governing without government. Polit Stud XLIV:652-667

Rhodes R (1997) Understanding Governance: policy networks, governance, reflexivity and accountability. Open University Press, Buckingham

Scolobig A, Vinchon C, Komendantova N, Bengoubou-Valerius M, Patt A, Gasparini P, Di Ruocco A, Baills A, Revellière A (2013) Social and institutional barriers to effective multi-hazard and multi-risk decision making and governance, Deliverable 6.3, Matrix project, New methodologies for multi-hazard and multi-risk assessment methods for Europe, European Commission 7th Framework Programme,134 pp. http://matrix.gpi.kit.edu/

Sharma U, Scolobig A, Patt A (2012) The effects of decentralization on the production and use of risk assessment: insights from landslide management in India and Italy. Nat Hazards 64:1357-1371

UN/ISDR (2005) Hyogo Framework for action 2005-2015: ISDR International Strategy for Disaster Reduction International Strategy for Disaster Reduction; Building the Resilience of Nations and Communities to Disasters. United Nations Development Programme, Geneva http://www.undp.org/ bcpr/whats_new/rdr_english.pdf, 09/03/07. Accessed 21 May 2013

van Asselt M, Renn O (2011) Risk governance. J Risk Res 14:431-449

van Kersbergen K, Van Waarden F (2004) Governance as a bridge between disciplines: cross-disciplinary inspiration regarding shifts in governance and problems of governability, accountability and legitimacy. Eur J Polit Res 43(2):143-171

Verweij M, Thompson M (eds) (2006) Clumsy solutions for a complex world: governance, politics, and plural perceptions. Palgrave Macmillan, New York

Walker G, Whittle R, Medd W, Watson N (2010) Risk governance and natural hazards. CapHaz-Net WP2 Report, Lancaster Environment Centre, Lancaster University, Lancaster. http://caphaz-net.org/ outcomes-results/CapHaz-Net_WP2_Risk-Governance2.pdf. Accessed 21 May 2013 
Walker G, Tweed F, Whittle R (2013) A framework for profiling the characteristics of risk governance in natural hazard contexts. Nat Hazards Earth Syst Sci Discuss 1:2207-2229. doi:10.5194/nhessd-1-22072013

Woo G (2011) Calculating catastrophe. Imperial College Press, London 